\title{
An independent fracturing water-flooding development method for shallow low-permeability thin oil layers in multi-layer sandstone reservoirs
}

\author{
Gao Dapeng, ${ }^{\mathrm{a}, *}$, Ye Jigen ${ }^{\mathrm{b}}$, Wang Tianjiao ${ }^{\mathrm{c}}$, Zhao Liang ${ }^{\mathrm{b}}$, Pan Songqi ${ }^{\mathrm{b}}$, Sun Zhenglong ${ }^{\mathrm{d}}$ \\ a Institute of Mechanics, Chinese Academy of Sciences, Beijing, 100190, China \\ ${ }^{\mathrm{b}}$ Research Institute of Petroleum Exploration \& Development, PetroChina, Beijing, 100083, China \\ ${ }^{c}$ Beijing Petroleum Machinery Company Limited, Beijing, 102206, China \\ ${ }^{\mathrm{d}}$ Xinjiang Oilfield 1st Oil Production Factory, PetroChina, Karamay, 252000, China
}

\section{A R T I C L E I N F O}

\section{Keywords:}

Extreme high water content

Independent development methods

Low-permeability thin oil layers

Stratified hydraulic fracturing

Gray relative analysis

Numerical reservoir simulation

\begin{abstract}
A B S T R A C T
Lots of multi-layer heterogeneous sandstone reservoirs have reached extreme high water content and high recovery after long-time water-flooding development, and their low-permeability thin oil layers (LPTOLs) have gradually been the main potential reserves. Therefore, taking the geology of LPTOLs into account, an independent water-flooding development (IWD) method with stratified hydraulic fracturing (SHF) for LPTOLs is put forward. The method combines undeveloped LPTOLs as an individual strata series in one injection-production system, and the HPTOLs even with low water content are abandoned in order to reduce the reservoir vertical heterogeneity. To realize economic benefits, mature stratified hydraulic fracturing is necessary to increase production. The key of IWD is selecting and combining appropriate LPTOLs in an individual strata series.

Two development modes, OW-OL and WW-OL, are designed by different wells' perforations and the oil layers' distribution. The difference between these two modes mainly depends on whether the oil-wells perforate the HPTOLs connected with the LPTOLs. Upon an embedded fracture model for simulating hydraulic fractures, the oil production and water content of one LPTOL are calculated with different physical factors of reservoir and fractures. According to the cumulative oil production under different factors, their impact degrees are evaluated by gray relative analysis method. Permeability, oil layer thickness and oil viscosity are three main factors influencing the development of LPTOLs, and flow coefficient is a comprehensive index composed of these three factors. Therefore, the flow coefficient variation degree is a core indicator to evaluate the vertical heterogeneity of an individual strata series, and IWD will get better water-flooding effect with lower flow coefficient variation degree. In order to analyze the effect of IWD, 30 cases are designed with different flow coefficient variation degree, different thickness of HPTOL and different IWD modes. Oil production and water content variation of two development modes are studied by simulation. OW-OL mode is superior to the WW-OL mode on waterflooding recovery. That is because the oil is mainly produced from layered-LPTOLs with less water content, the vertical water-flooding efficiency is higher at the production side, and the whole displacement is more balanced in the whole OW-OL strata series. IWD of LPTOLs is not only suitable for Chinese sandstone oilfields, but also has a general significance for other multi-layer sandstone reservoirs owing high-potential LPTOLs.
\end{abstract}

\section{Introduction}

Low permeability thin oil layers (LPTOLs) mainly contain argillaceous siltstone, mudstone and calcium powder sandstone with oil immersion existing in multi-layer sandstone reservoir. Their permeability and oil content are obviously worse than the high permeability thick oil layers (HPTOLs) crosslink with them. Therefore, due to the simultaneous existence of LPTOLs and HPTOLs in these reservoirs, their vertical heterogeneity is very serious. Injection water will first enter the HPTOLs in the early stage of oilfield development, and most LPTOLs have not been developed due to the vertical heterogeneity. When the water content of multi-layer sandstone reservoir reaches extreme high in the later water-flooding development stage, LPTOLs will become the primary objects for future development. Due to the ineffective circling of injected water, the remaining potential of LPTOLs becomes more prominent (Gao et al., 2017).

The methods of improving the development effect of LPTOLs in the multi-layer reservoirs include: stratified water injection, well pattern infilling, profile control water shutoff and EOR (Hu et al., 2013; Wu et al., 2014; Mustoni et al., 2012; Mazen et al., 2014; Zhou et al., 2017;

\footnotetext{
* Corresponding author

E-mail address: gaodapeng@imech.ac.cn (G. Dapeng).
} 
Xiao et al., 2017). For a long time, the stratified water injection (SWI) technology in Daqing oilfield is widely used (Liu et al., 2013, 2017; Jalali et al., 2016). However, due to the size limitation of the packers, the number of segments of the water-well wellbore is close to the maximum limit, and the average ratio of water-flooding oil layers to whole oil layers is still less than $50 \%$. It is too difficult to develop the LPTOLs by SWI in multi-layer reservoir (Gao et al., 2016). The focus of the tertiary infilling well pattern is the LPTOLs in Daqing oilfield, but the average daily oil production of the tertiary infilling wells drilling in 2010 is less than $1.5 \mathrm{t}$ per day, and their average water content has reached $85 \%$ during initial development stage. In addition, due to the restrictions of blocking agent and control mechanisms, deep profile control is not mature enough for multi-layer thick reservoir with ultrahigh water content (Xiong and Tang, 2007). Polymer flooding, compound flooding and other EOR technologies have also achieved very good effects in Daqing oilfield (Zhu et al., 2013). However, these technologies mainly focus on improving the water-flooding efficiency of HPTOLs. It is lack of applicability for the LPTOLs with extreme low porosity, low permeability and poor horizontal connectivity. In this paper, an independent water-flooding development method with stratified hydraulic fracturing for LPTOLs is put forward. In short, IWD, aiming at solving interlayer conflicts causing by vertical heterogeneity, combines many LPTOLs as an independent water-flooding development strata series, and stratified hydraulic fracturing is utilized to achieve economic productivity. The key lies in how to design an independent development model and how to optimally combine LPTOLs. Through IWD of LPTOLs, the recovery is improved compared to the conventional commingling exploitation of LPTOLs and HPTOLs.

Through analyzing LPTOLs geology and development status, whether LPTOLs meet the conditions of the independent development, and whether it is necessary to adopt IWD at this stage are determined. Both LPTOLs and HPTOLs of Daqing oilfield belong to the same river delta sedimentary system, and LPTOLs are regarded as the continuation of the HPTOL sandstone reservoir. LPTOLs are dominated by outer edge of the delta front facies, and they are crosslink with the HPTOLs. Therefore, it's difficult to divide the boundary of LPTOLs on the plane. In Daqing oilfield, the threshold value of one LPTOL's thickness is $1 \mathrm{~m}$ according their Business standard, which helps differentiate LPTOLs from HPTOLs, and the threshold value will has some minor differences in different oilfield. There are mainly three kinds of contact ways between LPTOLs and HPTOLs: layer-type, connect-type and lens-type, as shown in Fig. 1. Layer-type LPTOLs, generally extending more than $600 \mathrm{~m}$, have the biggest plane distribution scale among these kinds of LPTOLs. Connect-type LPTOLs have the second largest scale, and the lens-type LPTOL is the smallest type. The preliminary estimate of the geological reserves of LPTOLs is $7.2 \times 10^{8} \mathrm{t}$ and the recoverable reserves are 1.4-1.8 $\times 10^{8} \mathrm{t}$ in Daqing oilfield.

From Fig. 1, we can find that all four sets of well patterns have perforated the LPTOLs from initial development, containing elementary well pattern, first infilling well pattern, secondary infilling well pattern and tertiary infilling well pattern. The perforating thickness ratio (PTR, the ratio of the perforation thickness to the total thickness of the reservoir) gradually increases, while the average PTR reaches more than $55 \%$ after tertiary infilling wells perforating the reservoir. According to the monitoring data of coring wells in Daqing oilfield, the remaining potentials of LPTOLs are analyzed. Connect-type LPTOLs have been better developed by water-flooding in the past, and its water-flooding producing ratio (WPR, ratio of oil layers produced by water-flooding to the whole layers perforated) is $65.4 \%$, and the WPR of both the layertype and lens-type LPTOLs is only $11.8 \%$, so there is enough potential in the layer-type and lens-type LPTOLs. Besides, because the scale of lenstype LPTOLs is quite limited, the layer-type LPTOLs are the key of IWD.

From the water-flooding development status of LPTOLs, we find two main problems. First, although LPTOLs are perforated in tertiary infilling well pattern at extreme high water content stage, the vast majority of injected water enters the main oil layers with ineffective circulation, and LPTOLs have not been developed effectively during conventional water-flooding process. Secondly, LPTOLs have poor physical and oil-bearing properties, and their productivities are very limited, so hydraulic fracturing is needed for them to achieve economic performance (Fu et al., 2003). The new wells' oil production has been less than $2 \mathrm{t} / \mathrm{d}$ these years in Daqing oilfield, and they present quickening production decline trend. Mature technologies of HPTOLs can't solve the decline problems of LPTOLs. The effects of conventional stimulation measures are quite limited for LPTOLs, such as well pattern infilling, stratified layered water injection. From 2010 to 2015, with the increasing of stratified layered water injection segments, single well segments reach 6 and even 10, but the average WPR is still less than 50\% (Gao et al., 2015, 2016). In addition, the layer-type LPTOLs have obtained satisfied performance during an individual oil test (Liu et al., 1996). Because most LPTOLs' depth are quite shallow $(<1000 \mathrm{~m})$ in Daqing oilfield, the average fracturing pressure gradient is generally greater than the vertical stress gradient, so horizontal fractures are mainly formed in LPTOLs after hydraulic fracturing according to the analysis of core observation and micro seismic (Zhou et al., 1982; Sung and Ertekin, 1987; Zhao et al., 2001; Larsen, 2011). Therefore, stratified hydraulic fracturing has been applied maturely in Daqing oilfield. It will help LPTOLs achieve economic performance in the future. To sum up, the combination of enough LPTOLs has the capacity of IWD after SHF, and it is necessary for LPTOLs to adopt IWD with SHF, the

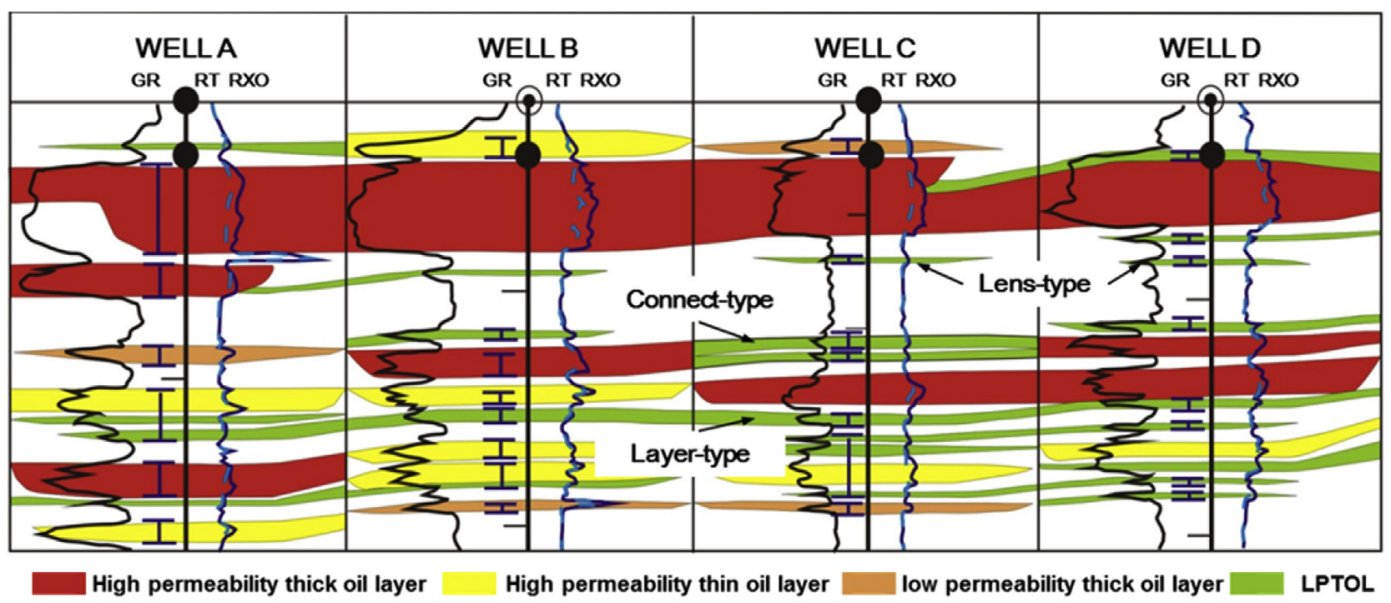

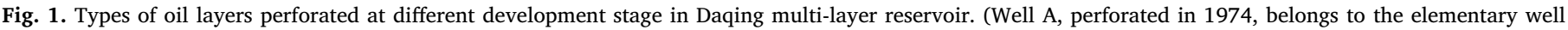

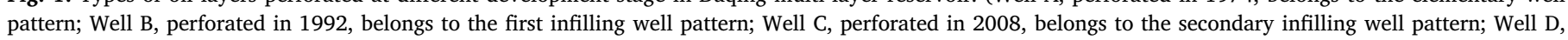
perforated in 2017, belongs to the tertiary infilling well pattern utilizing IWD.) 


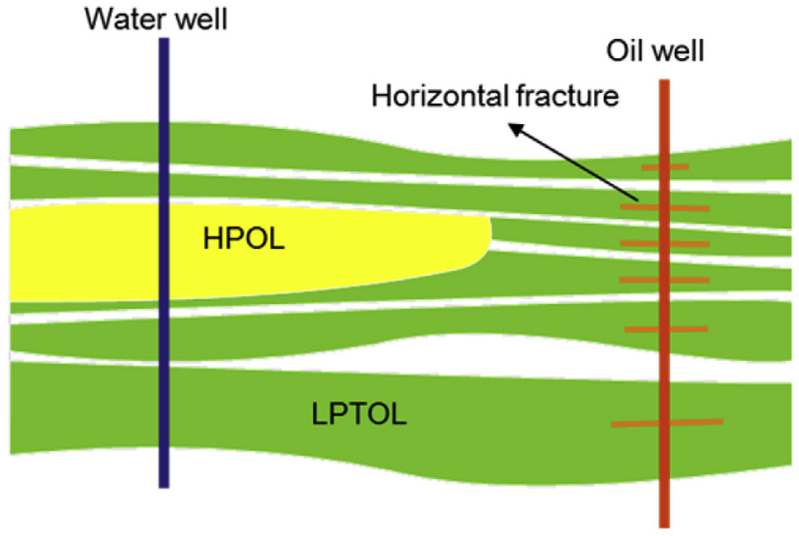

Fig. 2. Sketch of OW-OL mode.

IWD modes and numerical simulation of LPTOLs with SHF are needed to study further.

\section{Two IWD modes of LPTOLs}

\subsection{OW-OL mode}

As shown in Fig. 2, OW-OL means the oil-well only perforate layertype LPTOLs, and the perforation layers of the adjacent water-well are determined upon the space distribution of these LPTOLs, in ensuring that these LPTOLs can be developed by a complete water-flooding well pattern. In the OW-OL mode, the water-well's perforation layers generally contain a small amount of HPTOLs. The oil-well is stimulated by SHF for developing these LPTOLs, and the injected water has a better flooding effect in this well pattern because of the HPTOLs perforated by the water-well. Especially, the injected water enters the LPTOLs totally under the injection-production pressure difference. Due to the weak heterogeneity in the production side, the productivity of the LPTOLs perforated by the oil-well can be more balanced.

\subsection{WW-OL mode}

As shown in Fig. 3, WW-OL means the water-well only perforate layer-type LPTOLs, and the perforation layers of the adjacent oil-well are determined upon the space distribution of these LPTOLs, in ensuring that these LPTOLs can be developed by a complete waterflooding well pattern. In the WW-OL mode, the oil-well's perforation layers generally contain a small amount of HPTOLs. The oil-well is stimulated by SHF for developing these LPTOLs, and both LPTOLs and HPTOLs are developed by the oil-well. However, a considerable part of the injected water flows from the LPTOLs into the HPTOLs, so the

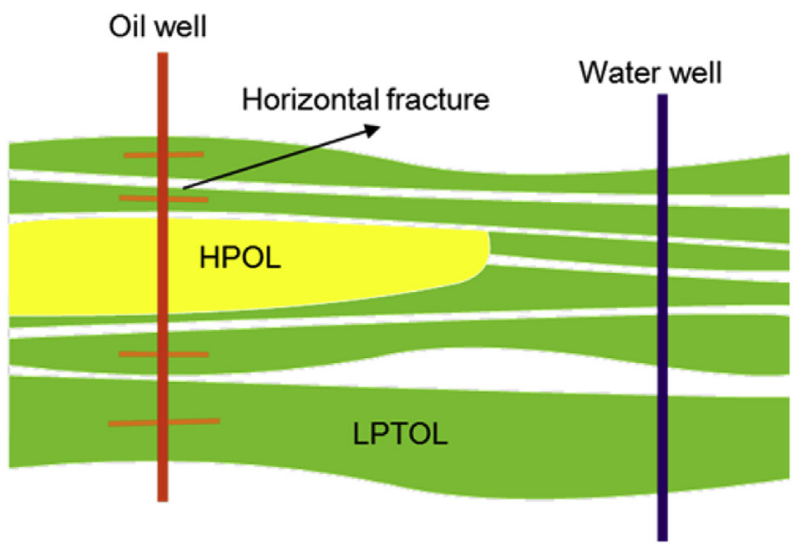

Fig. 3. Sketch of WW-OL mode.

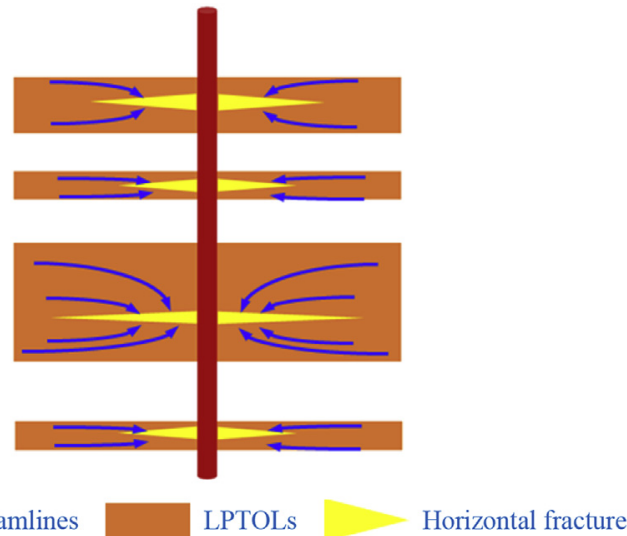

Fig. 4. Flow streamlines in LPTOLs with horizontal fractures.

water-flooding effect of the LPTOLs is influenced. HPTOLs with extra high water content may lead to ineffective cycle of the injected water.

The differences between these two modes concentrate on whether the oil-wells perforated the HPTOLs. Therefore, deploying the IWD well pattern needs the analysis of the LPTOLs and HPTOLs geology in field applications. In order to choose the more reasonable IWD modes scientifically, a numerical reservoir model with horizontal fractures is given to forecast the LPTOLs' performance and evaluate the core impact factors for IWD strata series design.

\section{A numerical model of oil layers with horizontal fractures}

\subsection{Assumptions}

The horizontal fractures' surfaces are perpendicular to the direction of the wellbore, and horizontal fractures have great influences on the fluid flow in the LPTOLs, as shown in Fig. 4. Considering the oil-water two-phase flow, the reservoir matrix and the horizontal fractures are regarded as two independent flow systems. According to the fluid flow mechanism between the fracture and the matrix, the connection condition of these two medium is established. Based on the material balance principle, the 3D oil-water two-phase flow model is established. The basic assumptions are shown as follows. (1)The horizontal fractures have limited conductivity, the fluid flow inside the fracture conforms to the Darcy seepage law. (2) The oil only flows from the fractures to the wellbore. (3) The horizontal fracture is assumed to be a rectangular parallelepiped, its height is the average support width, and the fracture connect with the matrix through the top and bottom surfaces, the fluid only flows through the fracture surface of the upper and lower fractures. (4) The impact of capillary force is ignored.

\subsection{Mathematical model}

Horizontal fractures and matrix flow models include cumulative items, flow items and source sinks, respectively, as shown in Eq. (1) and Eq. (2). The matrix flow equation characterizes the fluid flow among adjacent matrix units and the crossflow between the matrix and the fracture units. The fracture flow equation characterizes the fluid flow among the adjacent fracture units, the well production from the fracture, and the crossflow between the fracture and the matrix, as in Eq. (3).

$$
\begin{aligned}
& \frac{\partial\left(\phi_{\mathrm{m}} V_{\mathrm{m}} b_{\mathrm{m}, l} S_{\mathrm{m}, \mathrm{l}}\right)}{\partial t}=\nabla\left[T_{\mathrm{m}, \mathrm{l}}\left(\nabla P_{\mathrm{m}}-\gamma_{\mathrm{l}} \nabla z_{\mathrm{m}}\right)\right]-q_{\mathrm{m}, \mathrm{f}, \mathrm{l}} \\
& \frac{\partial\left(\phi_{\mathrm{f}} V_{\mathrm{f}} b_{\mathrm{f}, l} S_{\mathrm{f}, l}\right)}{\partial t}=\nabla\left[T_{\mathrm{f}, l} \cdot\left(\nabla P_{\mathrm{f}}-\gamma_{l} \nabla z_{\mathrm{f}}\right)\right]+q_{\mathrm{f}, \mathrm{m}, l}-q_{\mathrm{w}, l} \\
& q_{\mathrm{f}, \mathrm{m}, l}=T_{\mathrm{f}, \mathrm{m}, l} \cdot \Delta P_{\mathrm{f}, \mathrm{m}}
\end{aligned}
$$


The initial conditions are shown in Eq. (4).

$\left.P\right|_{t=0}=P_{i},\left.\quad S\right|_{t=0}=S_{i}$

The inner boundary and outer boundary conditions are shown in Eq. (5).

$\left.P\right|_{\Gamma_{\mathrm{w}}}=P_{\mathrm{w}},\left.\frac{d P}{d n}\right|_{\Gamma_{\mathrm{e}}}=0$

The transmissivity between the fracture and the matrix is calculated by Eq. (6).

$T_{\mathrm{f}, \mathrm{m}, l}=\frac{K_{\mathrm{f}, \mathrm{z}} K_{\mathrm{rl}}}{B_{l} \mu_{l}} \cdot \frac{A_{\mathrm{f}, \mathrm{m}}}{\bar{d}_{\mathrm{f}, \mathrm{m}}}$

\subsection{Model solving}

Orthogonal structure grids are used to divide the reservoir matrix, and the horizontal fractures are treated as virtual unstructured grids in the matrix. The meshing results of the matrix and fracture are shown in Fig. 5.

The recording processes of the fracture grids and the matrix grids are independent with each other. In the reservoir numerical simulation model, only the adjacent grids have fluid exchange due to the existence of pressure differences. Therefore, it is necessary to define a nonneighboring connection (NNC) records the relationship between the fracture grid and the underlying matrix grid. In Fig. 6, NNC1 to NNC6 are non-neighboring connections established according to the matrix and fracture grids shown in Fig. 5. NNC1 to NNC5 are non-neighboring connections between the fracture and the matrix, and NNC6 is nonneighboring connections between well and fracture, and $\mathrm{m} 1 \sim \mathrm{m} 16$ are 16 matrix grids, $\mathrm{f} 1 \sim \mathrm{f} 5$ are 5 fracture grids.

The residual equations of each grid node in the matrix and fracture are completely implicitly separated, as shown in Eqs. (7) and (8). And then the equation set of residual are obtained.

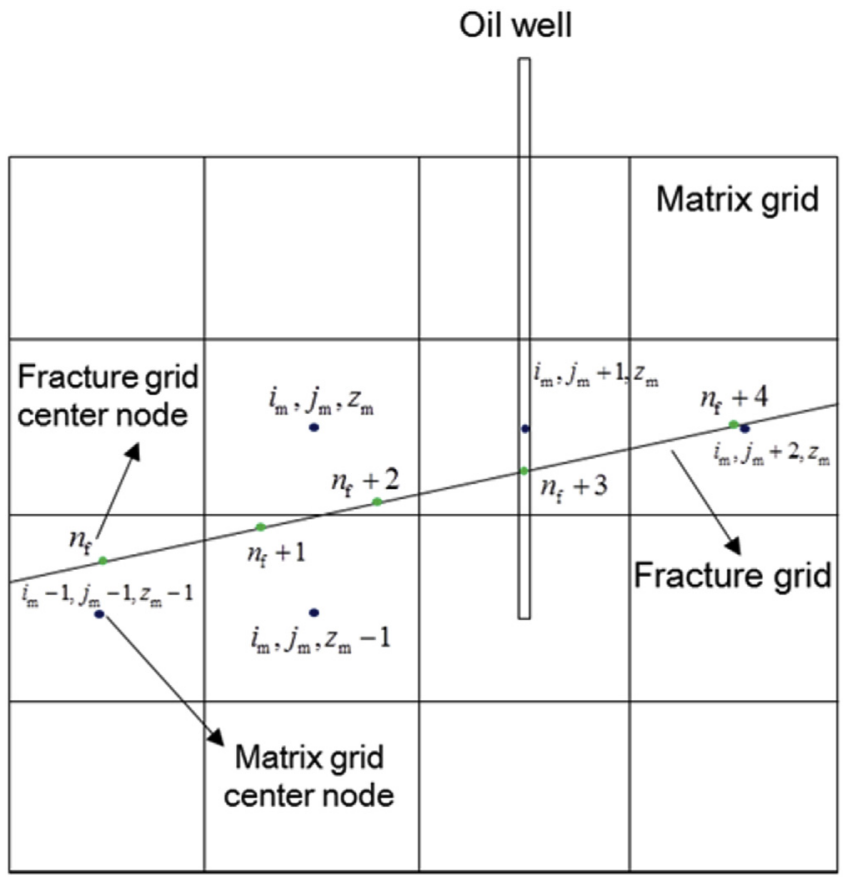

Fig. 5. Sketch of the meshing of matrix and fracture.

\begin{tabular}{|c|c|c|c|}
\hline$m_{13}$ & $m_{14}$ & $m_{15}$ & $m_{16}$ \\
& & & \\
$m_{9}$ & $m_{10} f_{3}$ & $m_{11} f_{4}$ & $m_{12} f_{3}$ \\
& $N N C_{3}$ & $N N C_{4}$ & $N N C_{5}$ \\
\hline$m_{5} f_{1}$ & $m_{6} f_{2}$ & $m_{7}$ & $m_{8}$ \\
$N N C_{1}$ & $N N C_{2}$ & & \\
\hline & & & \\
$m_{1}$ & $m_{2}$ & $m_{3}$ & $m_{4}$ \\
\hline
\end{tabular}

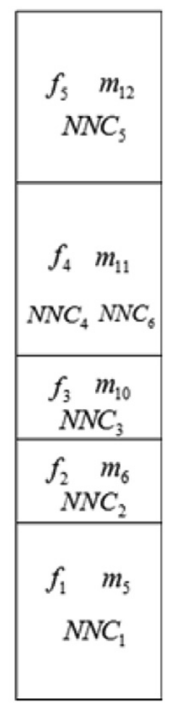

Fig. 6. Sketch of NNC.

$$
\begin{aligned}
R_{\mathrm{m}, l}= & \frac{\phi_{\mathrm{m}, c} V_{c}}{\Delta t}\left[\left(b_{\mathrm{m}, l, c} S_{\mathrm{m}, l, c}\right)^{n+1}-\left(b_{\mathrm{m}, l, c} S_{\mathrm{m}, l, c}\right)^{n}\right] \\
& -\sum_{a=1}^{B}\left[T_{\mathrm{m}, l, i, c}\left(\Delta P_{\mathrm{m}, l, i, c}-\gamma_{l} \Delta z_{\mathrm{m}, i, c}\right)\right]^{n+1}-q_{\mathrm{m}, l, \mathrm{w}}^{n+1}+q_{\mathrm{m}, l, c, N N C}^{n+1}
\end{aligned}
$$

$$
\begin{aligned}
R_{\mathrm{f}, l}= & \frac{\phi_{\mathrm{f}, c} V_{c}}{\Delta t}\left[\left(b_{\mathrm{f}, l, c} S_{l, \mathrm{f}, c}\right)^{n+1}-\left(b_{\mathrm{f}, l, c} S_{\mathrm{f}, l, c}\right)^{n}\right] \\
& -\sum_{a=1}^{B}\left[T_{\mathrm{f}, l, i, c}\left(\Delta P_{\mathrm{f}, l, i, c}-\gamma_{l} \Delta z_{\mathrm{f}, i, c}\right)\right]-q_{\mathrm{f}, l, w}^{n+1}+q_{\mathrm{f}, l, c, N N C}^{n+1}
\end{aligned}
$$

The finite difference equations of each grid form an equation group, and then a numerical model with a seven-diagonal sparse coefficient matrix is formed, as shown in Fig. 7.

In the solution of the numerical model, if the fracture is located inside the reservoir, the boundary condition is taken at both ends. If the fracture extends to the boundary of the reservoir, the boundary conditions at both ends are determined by the outer boundary condition of the reservoir (Hajibeigi et al., 2011). Finally, the model is solved considering horizontal fractures by the Matlab numerical calculation platform.

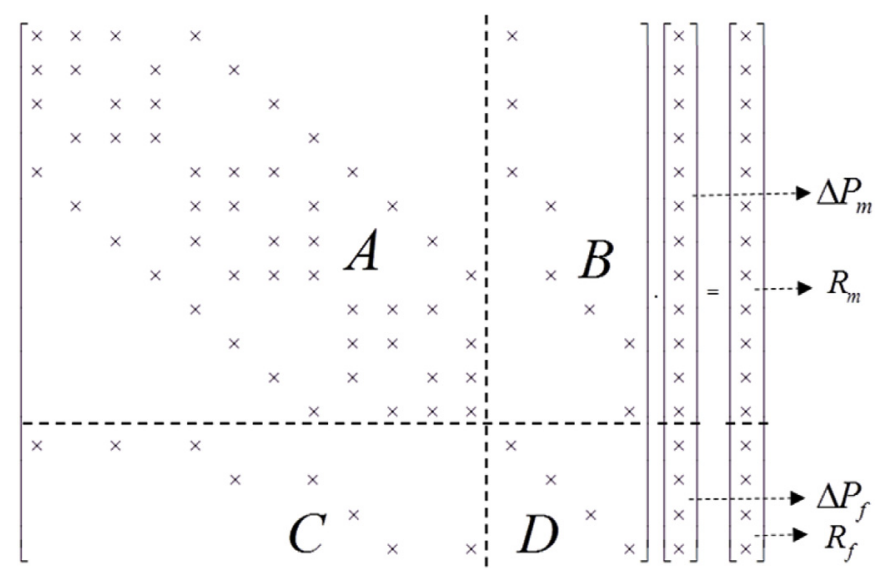

Fig. 7. Horizontal fracture numerical model matrix structure diagram. (A is the coefficient matrix of the grid pressure matrix, which is similar to the conventional three-dimensional reservoir seven diagonal matrix; $\mathrm{B}$ and $\mathrm{C}$ are the correlation coefficient matrix of the fracture and matrix grid pressure; $\mathrm{D}$ is the coefficient matrix of the fracture pressure grid.) 
Table 1

Basic parameters of the LPTOL water-flooding development model.

\begin{tabular}{lll}
\hline Parameters & Unit & Value \\
\hline Matrix permeability & $\mathrm{mD}$ & 10 \\
Thickness of the LPTOL & $\mathrm{m}$ & 0.5 \\
Fracture permeability & $\mathrm{mD}$ & 1670 \\
Rectangular fracture size (width $\times$ length) & $\mathrm{m}^{2}$ & $30 \times 50=1500$ \\
Initial oil saturation & $/$ & 0.45 \\
Injection pressure & $\mathrm{MPa}$ & 15 \\
Production pressure & $\mathrm{MPa}$ & 5 \\
Well space between injection well and production & $\mathrm{m}$ & 212 \\
$\quad$ & & \\
$\quad$ well & $/$ & $50 \times 50 \times 1=1500$ \\
Gumber of grid $(\mathrm{X} \times \mathrm{Y} \times \mathrm{Z}$ ) & $\mathrm{m}$ & 5 \\
Grid steps of $\mathrm{X}$ and $\mathrm{Y}$ directions & $\mathrm{m}$ & 0.5 \\
\hline
\end{tabular}

\section{Influence of different factors on LPTOLs' fracturing water- flooding development}

\subsection{Basic model parameters}

Based on the numerical reservoir simulation model considering the horizontal fractures, the influences of different factors on the fracturing development of LPTOLs are studied. The impact degree of each index on the cumulative amount of oil production is analyzed by gray correlation method, and then the key factors influencing the fracturing water-flooding development of LPTOLs are determined. In order to study the influences of different factors, a mechanism model is designed according to the mean parameters of LPTOLs in Daqing oilfield, as shown in Table 1 . These parameters are obtained from actual measurement data of different cores in Daqing oilfield.

In this model, the relative permeability curves of LPTOLs and HPTOLs are collected from Daqing oilfield, as shown in Fig. 8. The relative permeability curves reflect the macroscopic characteristics of

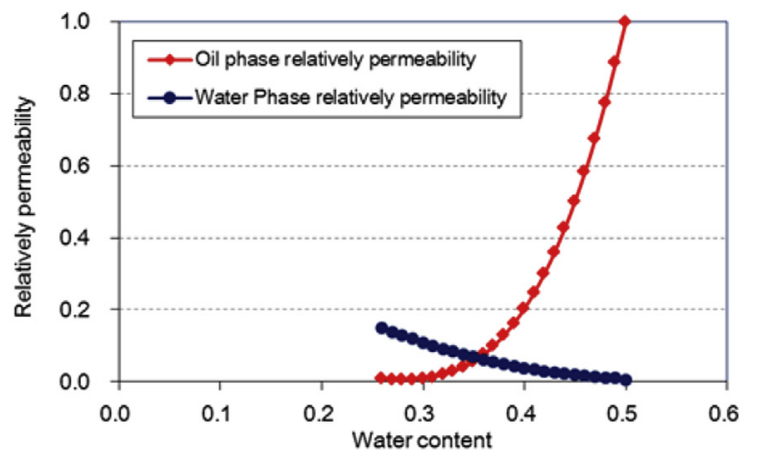

(a) Oil and water relative permeability in LPTOLs various complex micro-seepage physical phenomena in the multi-phase flow in porous media.

It is the most important function to characterize the law of multiphase flow, and its shape and variation also control and determine the dynamic development process of reservoirs. By comparison, the oil phase relative permeability is quite lower in the LPTOLs than that in HPTOLs. When the initial oil saturation is only $50.7 \%$, the water saturation of the curve intersection point is $66.7 \%$, and the two-phase span is $26.2 \%$, so the residuals are more difficult to develop by conventional water injection. With these basic parameters, the pressure and production of one LPTOL with 10 years water-flooding development (two injection wells and one production well) are calculated by the model.

\subsection{Influence of reservoir and fluid physical factors}

To discuss effect of the reservoir and fluid physical factors on the production dynamics of one single LPTOL with horizontal fractures, the oil layer's permeability is assumed to be $5 \mathrm{mD}, 10 \mathrm{mD}$ and $20 \mathrm{mD}$, and the thickness of the oil layers is assumed to be $0.2 \mathrm{~m}, 0.5 \mathrm{~m}$ and $1 \mathrm{~m}$, and oil viscosity is assumed to be $5 \mathrm{mPa}$, $10 \mathrm{mPa}$ s and $15 \mathrm{mPa}$ s, respectively. As can be seen from Fig. 9, with the increase of reservoir permeability, the descend trend of daily oil production is also more obvious in the middle and late period, and the daily oil production under different permeability is very close in the late period. The LPTOLs with different permeability have experienced the stable stage after the decline of initial production, and the higher the permeability the shorter stable production stage. That also means horizontal fractures get more obvious stimulation effect when the oil layer permeability is high, but that also leads to negative effects because of rapid growth of water content.

As shown in Fig. 10, the daily oil production is nearly proportional to the oil layer thickness in the later stage. When the thickness of the oil layer is large, the daily oil production does not show a significant decrease in the later stage, which is obviously different from the permeability's impact as shown in Fig. 9(a). In addition, the thickness

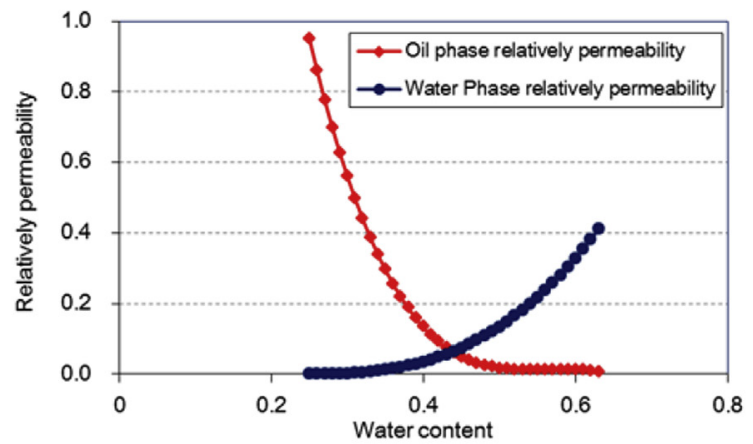

(b) Oil and water relative permeability in HPTOLs

Fig. 8. Oil and water relative permeability curves of both LPTOLs and HPTOLs.

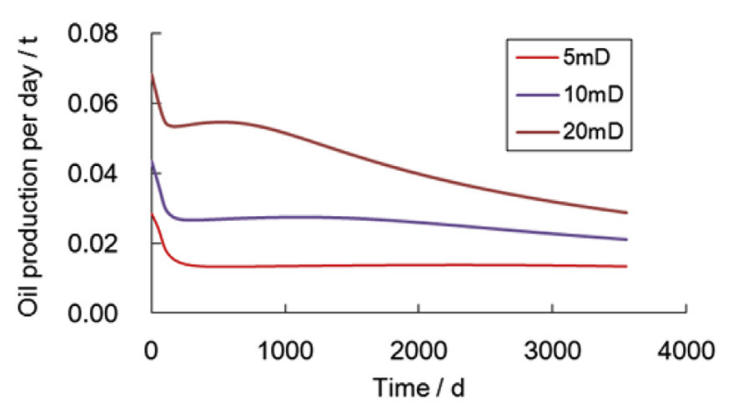

(a) Oil production per day

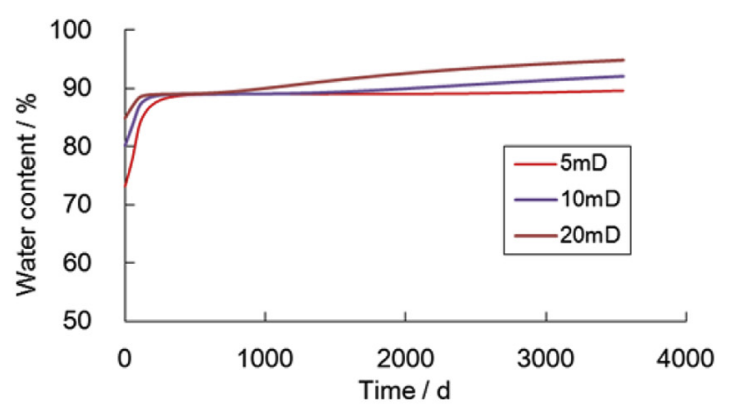

(b) Water content

Fig. 9. Oil production and water content dynamics of LPTOLs with different permeability. 


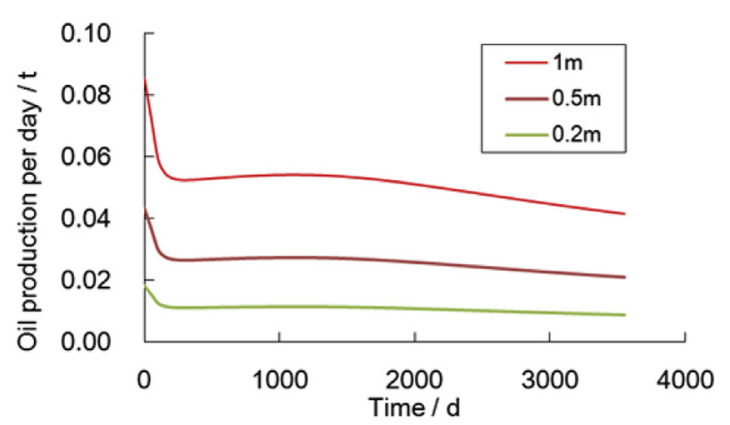

(a) Oil production per day

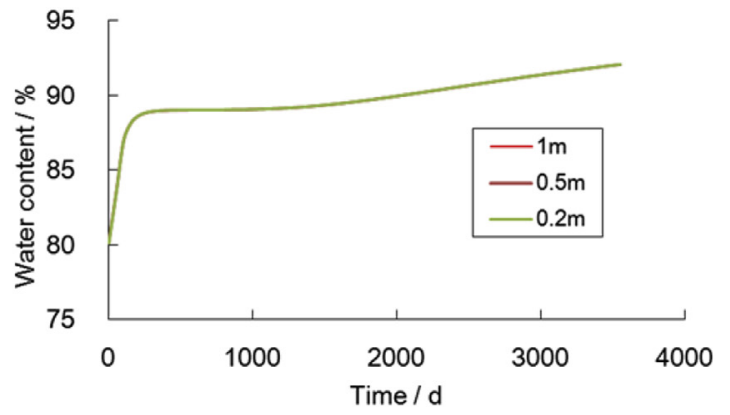

(b) Water content

Fig. 10. Oil production and water content dynamics of LPTOLs with different thicknesses.

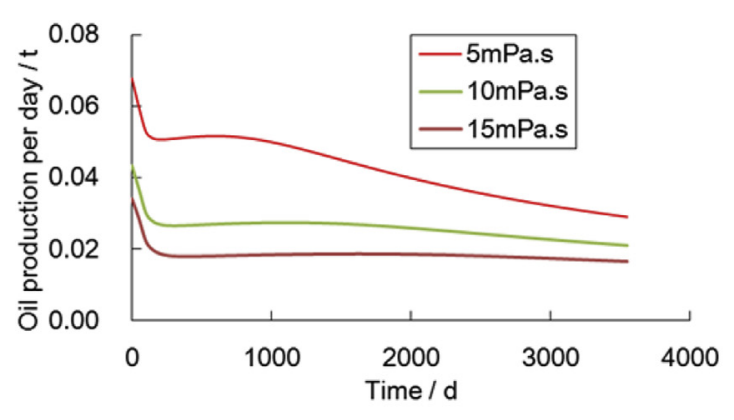

(a) Oil production per day

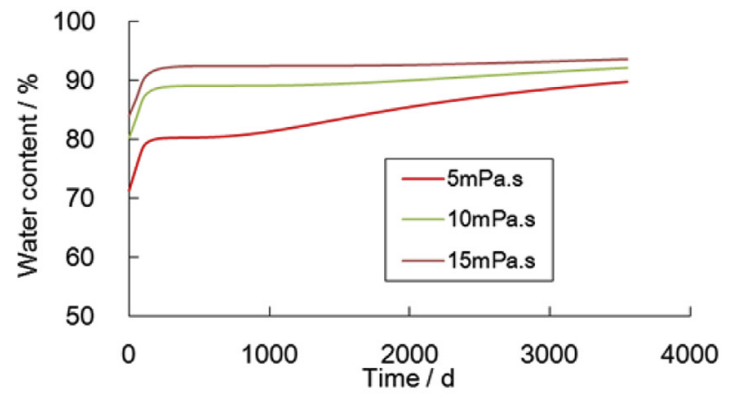

(b) Water content

Fig. 11. Oil production and water content dynamics of LPTOLs with different oil viscositys.

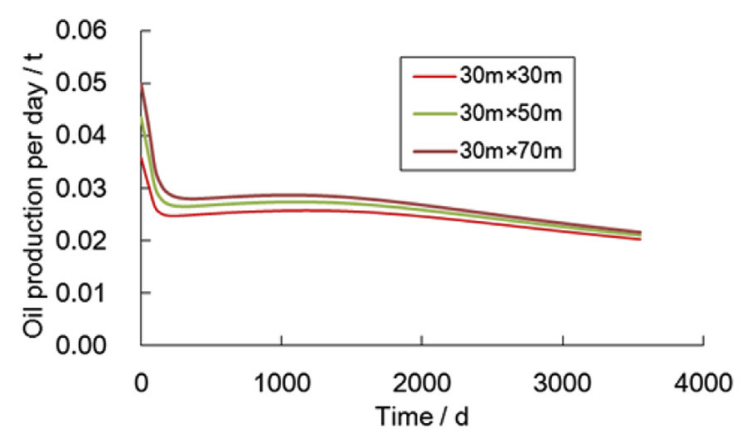

(a) Oil production per day

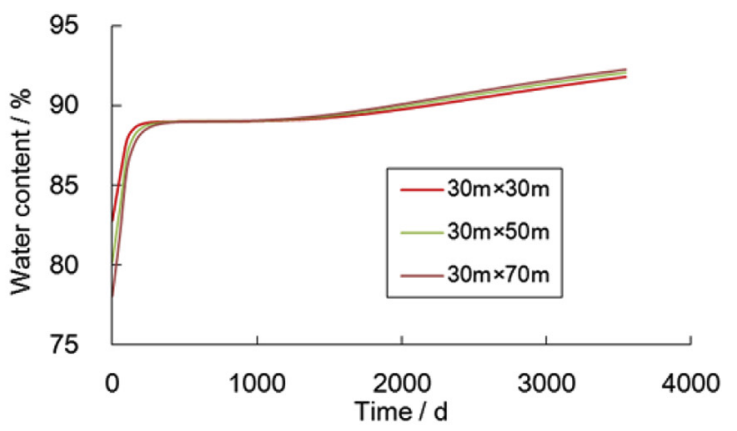

(b) Water content

Fig. 12. Oil production and water content dynamics of LPTOLs with different SRV size.

doesn't have any effect on water content.

As shown in Fig. 11, when the viscosity of the crude oil is greater, the oil production is lower. When the oil viscosity is small, the daily oil production has a fast attenuation. Besides, the water content remains at $85 \%-90 \%$. When the oil viscosity is small, the water content is small.

\subsection{Influence of horizontal fracture factors}

The stratification hydraulic fracturing process has been quite mature in many oilfields (Osiptsov, 2017). According to well test data statistics in Chinese Daqing oilfield, horizontal fracture dimensionless conductivities are assumed to be $0.001,0.01,1$ and 10 , and SRV size (width $\times$ length) is assumed to be $30 \mathrm{~m} \times 30 \mathrm{~m}, 30 \mathrm{~m} \times 50 \mathrm{~m}$ and $30 \mathrm{~m} \times 70 \mathrm{~m}$ respectively in the model. As shown in Fig. 12, SRV size has a greater impact on the daily oil production in the former production stage compared to the later stage. When the SRV size is smaller, the initial water content will be slightly higher, and the water content differences under different SRV sizes tend to be gradually smaller in the latter stage.
It can be seen from Fig. 13 that the oil production and water content is basically the same when the dimensionless fracture conductivity is 1-10. Besides, the oil production and the water content are significantly smaller than other cases when the dimensionless fracture conductivity is 0.001 . There is an inflection point, where the fracture conductivity increases to a certain extent, oil production per day will no longer increase (Cinco et al., 1978; Narasimhan and Palen, 1979). Normally, most hydraulic horizontal fractures' conductivities are larger than this inflection point. It can be observed that the oil production increases obviously when the horizontal fractures formed, so the satisfied performance can be obtained by SHF in shallow sandstone reservoirs.

\subsection{Impact degree evaluation}

LPTOLs' fracturing water-flooding development requires serious evaluation of different factors' impact, in order to select the appropriate LPTOLs for SHF and determine which LPTOLs are suitable for fracturing together to achieve economic productivity. Therefore, it's necessary to evaluate the impact degree of different factors. In this paper, the gray 


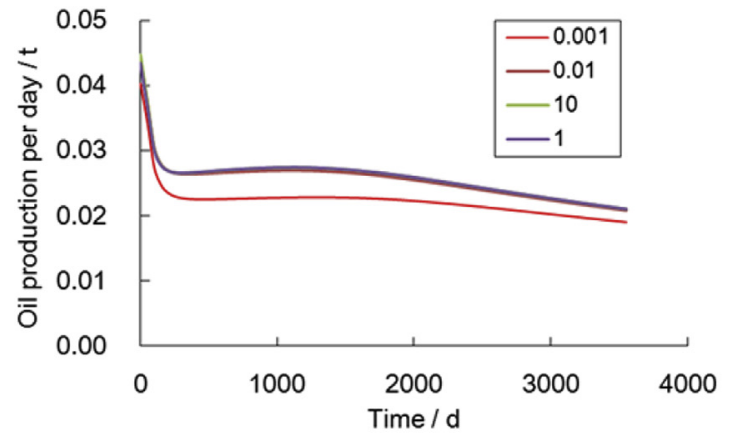

(a) Oil production per day

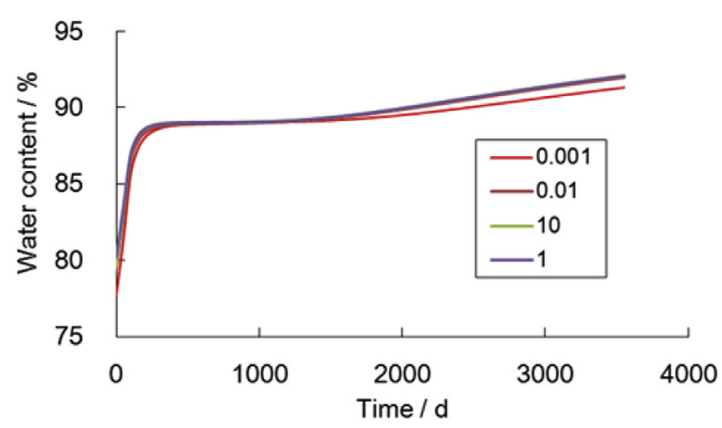

(b) Water content

Fig. 13. Oil production and water content dynamics of LPTOLs with different horizontal fracture conductivity.

factor analysis method is used to evaluate the main factors influencing the hydraulic fracturing effect of the shallow LPTOLs. In the process of system development, if the trend of the two factors change is consistent, that means a higher degree of synchronization changes, and that also can be described as a high degree of correlation; Li et al. (2011) used the single-objective gray situation decision-making method to combine the gray decision theory with various indexes reflecting the reservoir development effect. Considering the various factors reflecting the contradiction of reservoir layer, they construct the sample matrix and measure matrix of effect evaluation, so as to quickly determine the optimal scheme. Their results of case analysis and numerical simulation illustrate that the gray decision method is reliable and can solve the traditional problems effectively.

The gray relational analysis method is based on the similarity or dissimilarity of the trends among factors, and that is also regarded as the gray relational degree, a measure of the degree of correlation between the factors (Liu et al., 2009). This theory puts forward the concept of gray relational analysis of each subsystem, and finds out the quantitative relationship among the subsystems (or factors) through certain methods. Therefore, the gray relational analysis provides a quantitative measure of the development trend of a system, and it is very suitable for dynamic process analysis. Gray relational analysis is the basis of forecasting and decision making in gray system, and it is the quantitative analysis and comparison of dynamic development trend. The evaluation process is divided into three steps as follows. (a) We select the factors that can be used for the optimal factors, determining the influencing factors and the evaluation indexes, establishing the reference and comparing sequences; and we determined the cumulative oil production of each scheme as the evaluation index. (b) We adopt dimensionless processing of parameters' values in reference and comparison sequences. (c) The gray correlation coefficient and correlation degree $(C D)$ are calculated, and the degree of relevance is sorted.

\subsubsection{Data selection}

According to the model given before, one LPTOL's cumulative oil production are calculated under different factors, containing permeability, porosity, oil layer thickness, initial oil saturation, crude oil viscosity, injection-production pressure difference and fracture size. These parameters' value and the cumulative oil production of each program are shown in Table 2.

\subsubsection{Data columns processing}

The sequence values are dimensionless processed according to the comparison sequence of Table 2 (the second column in Table 2) and the corresponding reference sequence, and the results are shown in Table 3.

\subsubsection{Correlation coefficient calculation}

We firstly calculate the absolute difference between the comparison sequence $\left\{X_{i}(K)\right\}$ and the reference sequence $\left\{X_{0}(K)\right\}$, as shown in Table 4. And then we calculate the minimum value at each $K$ value in $\left|X_{i}(K)-X_{0}(K)\right|$, and choose the minimum one in all the minimum values of each $K$. After that, we calculate the maximum value at each $K$

Table 2

Influencing factors and accumulated oil production of different scheme.

\begin{tabular}{|c|c|c|c|c|c|c|c|c|c|c|c|c|c|c|c|}
\hline Factors & 1 & 2 & 3 & 4 & 5 & 6 & 7 & 8 & 9 & 10 & 11 & 12 & 13 & 14 & 15 \\
\hline Cumulative oil production/t & 49.1 & 90.8 & 150.9 & 38.1 & 179.5 & 148.7 & 65.1 & 63.1 & 111.9 & 21.4 & 37.6 & 85.8 & 94.8 & 87.4 & 93.3 \\
\hline Permeability/mD & 5 & 10 & 20 & 10 & 10 & 10 & 10 & 10 & 10 & 10 & 10 & 10 & 10 & 10 & 10 \\
\hline Oil layer thickness/m & 0.5 & 0.5 & 0.5 & 0.2 & 1.0 & 0.5 & 0.5 & 0.5 & 0.5 & 0.5 & 0.5 & 0.5 & 0.5 & 0.5 & 0.5 \\
\hline Viscosity/mPa's & 10 & 10 & 10 & 10 & 10 & 5 & 15 & 10 & 10 & 10 & 10 & 10 & 10 & 10 & 10 \\
\hline Injection - production pressure difference/MPa & 15 & 15 & 15 & 15 & 15 & 15 & 15 & 10 & 20 & 15 & 15 & 15 & 15 & 15 & 15 \\
\hline Initial oil saturation/f & 0.45 & 0.45 & 0.45 & 0.45 & 0.45 & 0.45 & 0.45 & 0.45 & 0.45 & 0.37 & 0.40 & 0.45 & 0.45 & 0.45 & 0.45 \\
\hline Porosity/f & 0.18 & 0.18 & 0.18 & 0.18 & 0.18 & 0.18 & 0.18 & 0.18 & 0.18 & 0.18 & 0.18 & 0.18 & 0.18 & 0.15 & 0.21 \\
\hline
\end{tabular}

Table 3

Data columns after dimensionless processing.

\begin{tabular}{|c|c|c|c|c|c|c|c|c|c|c|c|c|c|c|c|}
\hline Factors & 1 & 2 (reference column) & 3 & 4 & 5 & 6 & 7 & 8 & 9 & 10 & 11 & 12 & 13 & 14 & 15 \\
\hline Cumulative oil production & 0.541 & 1 & 1.663 & 0.419 & 1.977 & 1.637 & 0.717 & 0.695 & 1.233 & 0.236 & 0.414 & 0.945 & 1.044 & 0.962 & 1.027 \\
\hline Permeability & 0.5 & 1 & 2 & 1 & 1 & 1 & 1 & 1 & 1 & 1 & 1 & 1 & 1 & 1 & 1 \\
\hline Oil layer thickness & 1 & 1 & 1 & 0.4 & 2 & 1 & 1 & 1 & 1 & 1 & 1 & 1 & 1 & 1 & 1 \\
\hline Viscosity & 1 & 1 & 1 & 1 & 1 & 0.5 & 1.5 & 1 & 1 & 1 & 1 & 1 & 1 & 1 & 1 \\
\hline Injection - production pressure difference & 1 & 1 & 1 & 1 & 1 & 1 & 1 & 0.667 & 1.333 & 1 & 1 & 1 & 1 & 1 & 1 \\
\hline Initial oil saturation & 1 & 1 & 1 & 1 & 1 & 1 & 1 & 1 & 1 & 0.822 & 0.889 & 1 & 1 & 1 & 1 \\
\hline Porosity & 1 & 1 & 1 & 1 & 1 & 1 & 1 & 1 & 1 & 1 & 1 & 1 & 1 & 0.833 & 1.167 \\
\hline
\end{tabular}


Table 4

$\left|\boldsymbol{X}_{\boldsymbol{i}}(\boldsymbol{K})-\boldsymbol{X}_{0}(\boldsymbol{K})\right|$ value.

\begin{tabular}{|c|c|c|c|c|c|c|c|c|c|c|c|c|c|c|c|}
\hline Factors & 1 & 2 & 3 & 4 & 5 & 6 & 7 & 8 & 9 & 10 & 11 & 12 & 13 & 14 & 15 \\
\hline Cumulative oil production & 0.041 & 0.000 & 0.337 & 0.581 & 0.977 & 0.637 & 0.283 & 0.305 & 0.233 & 0.764 & 0.586 & 0.055 & 0.044 & 0.038 & 0.027 \\
\hline Permeability & 0.459 & 0.000 & 0.663 & 0.019 & 0.023 & 0.637 & 0.283 & 0.305 & 0.233 & 0.764 & 0.586 & 0.055 & 0.044 & 0.038 & 0.027 \\
\hline Oil layer thickness & 0.459 & 0.000 & 0.663 & 0.581 & 0.977 & 1.137 & 0.783 & 0.305 & 0.233 & 0.764 & 0.586 & 0.055 & 0.044 & 0.038 & 0.027 \\
\hline Viscosity & 0.459 & 0.000 & 0.663 & 0.581 & 0.977 & 0.637 & 0.283 & 0.029 & 0.101 & 0.764 & 0.586 & 0.055 & 0.044 & 0.038 & 0.027 \\
\hline Injection - production pressure difference & 0.459 & 0.000 & 0.663 & 0.581 & 0.977 & 0.637 & 0.283 & 0.305 & 0.233 & 0.586 & 0.475 & 0.055 & 0.044 & 0.038 & 0.027 \\
\hline Initial oil saturation & 0.459 & 0.000 & 0.663 & 0.581 & 0.977 & 0.637 & 0.283 & 0.305 & 0.233 & 0.764 & 0.586 & 0.345 & 0.356 & 0.438 & 0.373 \\
\hline Porosity & 0.041 & 0.000 & 0.337 & 0.581 & 0.977 & 0.637 & 0.283 & 0.305 & 0.233 & 0.764 & 0.586 & 0.055 & 0.044 & 0.038 & 0.027 \\
\hline
\end{tabular}

Table 5

Correlation coefficient.

\begin{tabular}{|c|c|c|c|c|c|c|c|c|c|c|c|c|c|c|c|}
\hline Factors & 1 & 2 & 3 & 4 & 5 & 6 & 7 & 8 & 9 & 10 & 11 & 12 & 13 & 14 & 15 \\
\hline Cumulative oil production & 0.933 & 1.000 & 0.628 & 0.495 & 0.368 & 0.471 & 0.667 & 0.651 & 0.710 & 0.427 & 0.492 & 0.911 & 0.928 & 0.938 & 0.955 \\
\hline Permeability & 0.553 & 1.000 & 0.462 & 0.968 & 0.961 & 0.471 & 0.667 & 0.651 & 0.710 & 0.427 & 0.492 & 0.911 & 0.928 & 0.938 & 0.955 \\
\hline Oil layer thickness & 0.553 & 1.000 & 0.462 & 0.495 & 0.368 & 0.333 & 0.421 & 0.651 & 0.710 & 0.427 & 0.492 & 0.911 & 0.928 & 0.938 & 0.955 \\
\hline Viscosity & 0.553 & 1.000 & 0.462 & 0.495 & 0.368 & 0.471 & 0.667 & 0.952 & 0.849 & 0.427 & 0.492 & 0.911 & 0.928 & 0.938 & 0.955 \\
\hline Injection - production pressure difference & 0.553 & 1.000 & 0.462 & 0.495 & 0.368 & 0.471 & 0.667 & 0.651 & 0.710 & 0.492 & 0.545 & 0.911 & 0.928 & 0.938 & 0.955 \\
\hline Initial oil saturation & 0.553 & 1.000 & 0.462 & 0.495 & 0.368 & 0.471 & 0.667 & 0.651 & 0.710 & 0.427 & 0.492 & 0.623 & 0.615 & 0.565 & 0.604 \\
\hline Porosity & 0.933 & 1.000 & 0.628 & 0.495 & 0.368 & 0.471 & 0.667 & 0.651 & 0.710 & 0.427 & 0.492 & 0.911 & 0.928 & 0.938 & 0.955 \\
\hline
\end{tabular}

value $\operatorname{in}\left|X_{i}(K)-X_{0}(K)\right|$, and then the maximum one is chosen from all maximum values of each $K$. Correlation coefficient can be calculated as follow:

$\xi_{i}(k)=\frac{\min _{l} \min _{k}\left|X_{i}(K)-\mathrm{X}_{0}(\mathrm{~K})\right|+\rho \max _{l} \max _{k}\left|X_{i}(K)-\mathrm{X}_{0}(\mathrm{~K})\right|}{\left|X_{i}(K)-\mathrm{X}_{0}(\mathrm{~K})\right|+\rho \max _{l} \max _{k}\left|X_{i}(K)-\mathrm{X}_{0}(\mathrm{~K})\right|}$

Eq. (9) is used to calculate the correlation coefficient by assuming the resolution coefficient $\rho=0.5$, you can calculate the correlation sequence and the reference sequence correlation coefficient, and all the correlation coefficients are shown in Table 5.

\subsubsection{Correlation degree}

According to the data in Table 5, CDs of each factor are calculated based on Eq. (9) and the cumulative amount of oil production, and the results are shown in Table 6.

$r_{i}=\frac{1}{n} \sum_{k=1}^{n} \zeta_{i}(k)$

The classification of $C D$ s and the determination of main influencing factors provide a theoretical basis for the design of comprehensive IWD \& SHF cases and the analysis of the technical limits.

\subsubsection{LPTOLs' combination recommendations for IWD}

SHF is necessary for IWD of layer-type LPTOLs, and it is also very important to combine the oil layers suitable for IWD \& SHF. Considering LPTOLs' poor physical properties, such as low effective permeability, small geological distribution scale, poor horizontal connectivity and low natural production, the appropriate wells and layers for IWD \& SHF are selected based on the study of reservoir geology,

Table 6

Correlation degree.

\begin{tabular}{lll}
\hline Factors & Rank & Correlation degree \\
\hline Permeability & 1 & 0.740 \\
Oil layer thickness & 2 & 0.705 \\
Viscosity & 3 & 0.698 \\
Injection - production pressure difference & 4 & 0.676 \\
Initial oil saturation & 5 & 0.650 \\
Fracture size & 6 & 0.643 \\
Porosity & 7 & 0.580
\end{tabular}

well test data, logging data and development dynamic analysis.

From the correlation degree of reservoir and fluid influencing factors, it can be seen that there are many factors influencing the cumulative oil production of oil-wells with horizontal fractures, and the reservoir permeability is the most affected, followed by oil layer thickness, crude oil viscosity, injection-production pressure difference, initial oil saturation and the smallest impact of porosity successively. So it will be able to choose the permeability, oil layer thickness and crude oil viscosity flow coefficient as the main factors to determine whether the LPTOLs are suitable for IWD \& SHF. Secondly, it is necessary to consider the injection - production pressure difference, and whether the oil-wells and water-wells can connect with each other in the strata series of IWD, and even whether there can be more water-wells connected with one oil-well in order to produce enough pressure to overcome the threshold pressure in LPTOLs (Zeng et al., 2011). Finally, we need to consider the initial oil saturation, which standards for the initial water-flooding status of the LPTOLs. In addition, the variable range of the initial oil saturation is relatively small and the influence degree is relatively small. The fracturing can be selected in the LPTOLs with relatively good physical properties.

In general, when making use of SHF to develop ultra-high water phase multi-layer sandstone reservoir, the impact of the fracture parameters on the stimulation effect is not very obvious. Therefore, if we want to get a higher oil production, we should pay more attention to select the appropriate fracturing layers.

\section{Case study of IWD in multi-layer reservoirs}

\subsection{Case design}

According to the gray relational analysis and evaluation, permeability, oil layer thickness and oil viscosity are three main factors influencing the development of LPTOLs. Flow coefficient is a comprehensive index composed of permeability, oil viscosity and oil layer thickness. Besides the oil layer physical parameters, thickness ratio of the HPTOLs (TRH) also has an important influence to the development of the crosslink LPTOLs. Finally the IWD modes are also very important factors to field application. Therefore, flow coefficient, IWD modes and $T R H$ are taken as the main indexes to design different cases, the other parameters of LPTOLs are same to that in Table 1.

The flow coefficient variation $(\mathrm{CV})$ presents the flow coefficient difference of each oil layer. This index is a normalized measure of 


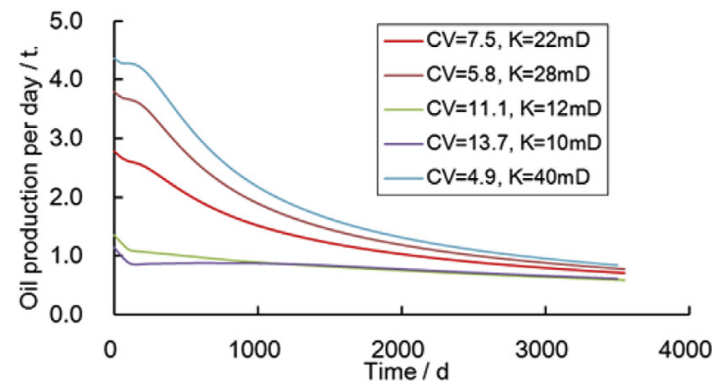

(a) Oil production per day

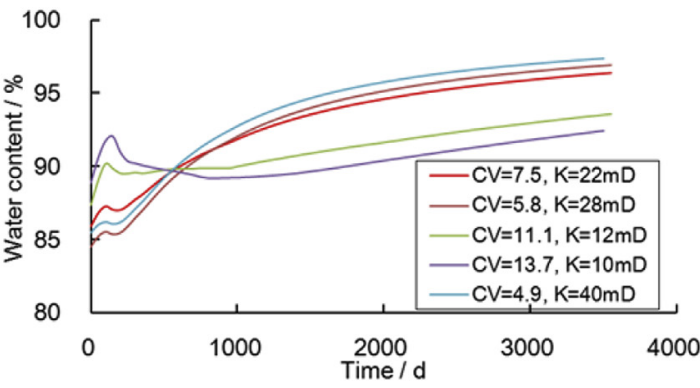

(b) Water content

Fig. 14. The oil production and water content of WW-OL development mode with $10 \%$ TRH.

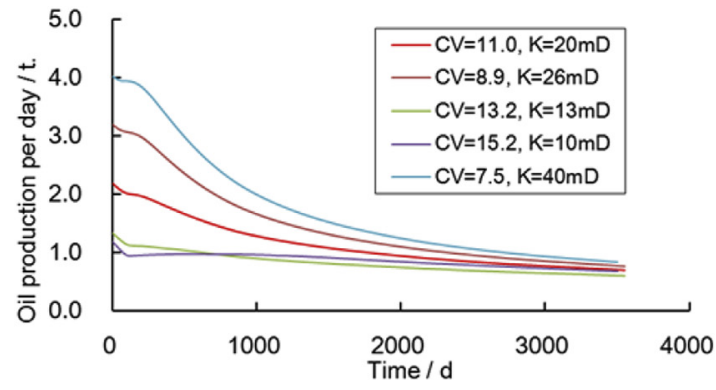

(a) Oil production per day

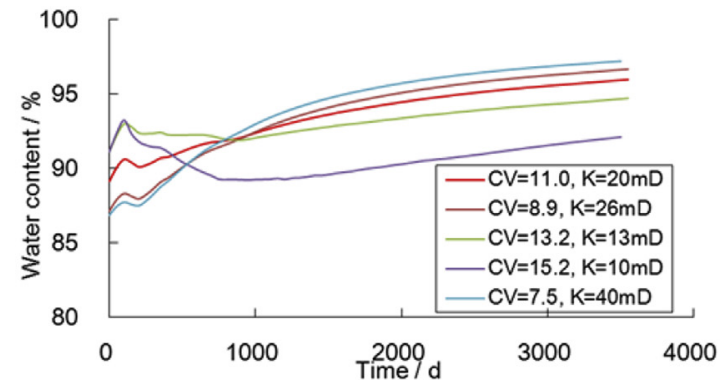

(b) Water content

Fig. 15. The oil production and water content of WW-OL development mode with $20 \% \mathrm{TRH}$.

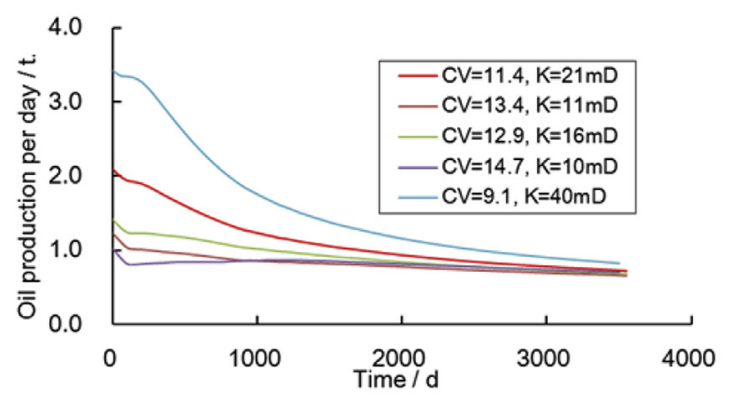

(a) Oil production per day

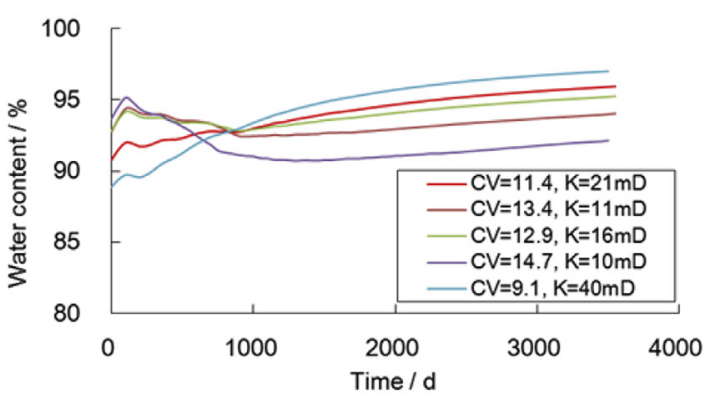

(b) Water content

Fig. 16. The oil production and water content of WW-OL development mode with 30\% TRH.

dispersion degree of the probability distribution, and $C V$ is defined as the ratio of flow efficiency standard deviation to average flow efficiency. Its mathematical definition is shown as follows.

$C V=\frac{M_{S D}}{M_{a}}$

Considering both HPTOLs and LPTOLs in one multi-layer reservoir, the $C V$ can be classified into five grades: extra high (14-15), high (11-14), medium (8-11), small (5-8), extra small (2-5). According to the distribution of the HPTOL and LPTOLs, TRH can be assumed to be $10 \%, 20 \%$ and $30 \%$ respectively in the designed cases, and the permeability of HPTOLs are assumed to be $200 \mathrm{mD} \sim 300 \mathrm{mD}$. According to the design method of orthogonal experiments, 30 different IWD \& SHF schemes are formed by cross combination, and the oil production and water content of each scheme are simulated. The total thickness of oil layers in each case is $10 \mathrm{~m}$, and the thickness of each LPTOL is $0.2 \mathrm{~m}-0.5 \mathrm{~m}$, the thickness of each HPTOL is $1 \mathrm{~m} \sim 3 \mathrm{~m}$. Three sample cases' details are shown in Appendix A, B and C.

\subsection{IWD dynamic of $W W-O L$}

From the oil production and water content dynamic curves of LPTOLs under WW-OL five-point well pattern water-flooding development mode (Figs. 14-16), we can obtain some conclusions as follows. (a) The initial daily oil production is relatively high for the multi-layer reservoirs with small $C V$ and high. However, the earlier stable production duration time is relatively short, and the oil production shows faster decline in later stage. This is because the initial injected water has not yet been flooded to the oil-well bottom during the earlier stage. The five - point well pattern pushes the injected water entering the SRV area quickly because of high reservoir permeability, causing the injected water reaches the oil-well quickly and the water content rises rapidly. (b) With the increasing of $C V$, the initial daily oil production gradually reduces. This is because developed HPTOLs leads to a high water content and low oil production at the initial production stage. (c) With the increasing of HPTOLs proportion, the oil production decreases, the stable production time cuts down and the water content raises. 


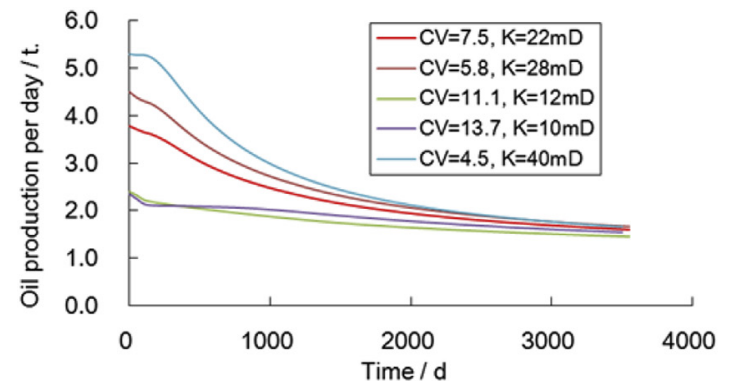

(a) Oil production per day

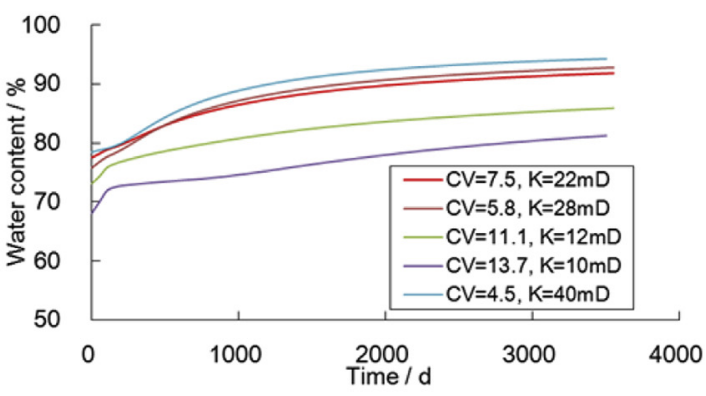

(b) Water content

Fig. 17. The oil production and water content of OW-OL development mode with $10 \%$ TRH.

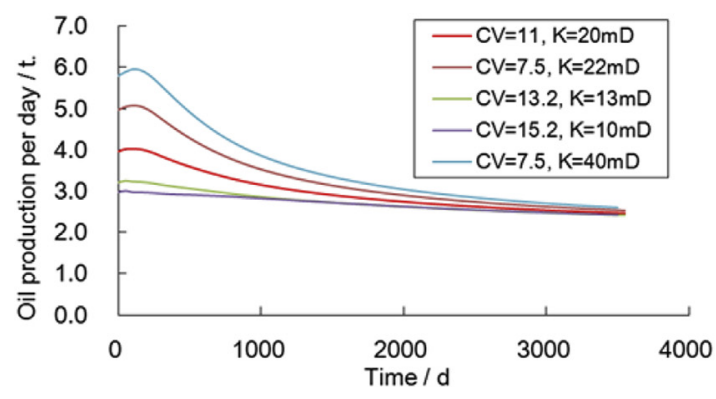

(a) Oil production per day

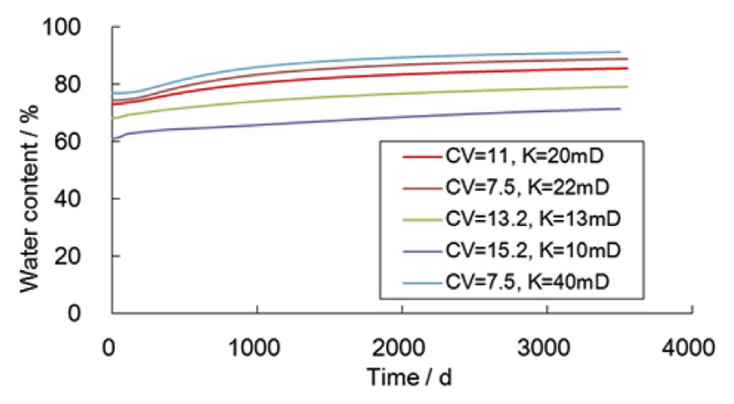

(b) Water content

Fig. 18. The oil production and water content of OW-OL development mode with $20 \%$ TRH.

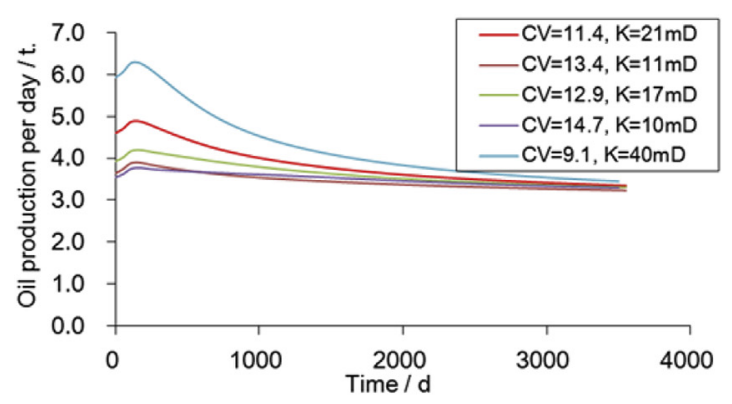

(a) Oil production per day

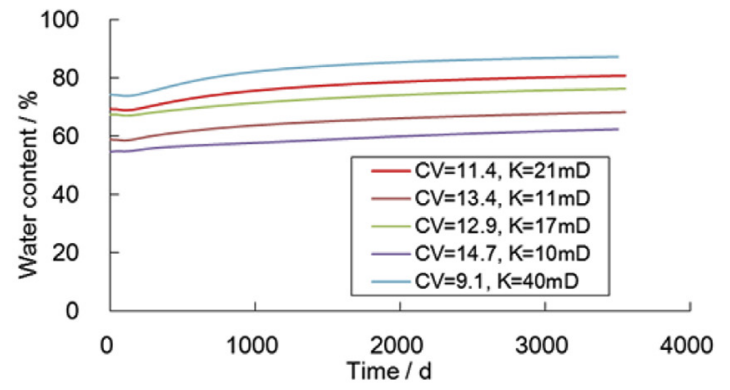

(b) Water content

Fig. 19. The oil production and water content of OW-OL development mode with $30 \% \mathrm{TRH}$.

\subsection{IWD dynamic of $O W-O L$}

The oil production and water content dynamics under OW-OL mode (Figs. 17-19) present better performances compared with that under WW-OL mode, and the main improvements are shown in these 3 points. (a) The highest daily oil production may increases to $5 \mathrm{t} \sim 6 \mathrm{t}$ per day in the earlier stage, and the oil production can still keep stable at $2 \mathrm{t} \sim 3 \mathrm{t}$ per day in the later production stage. (b) Water content significantly reduces, and the initial water content can be less than $80 \%$, but the water content rise quickly later. (c) When the $C V$ is relatively large $(C V=13.2$ and 15.2), the oil production keeps stable at about $3 \mathrm{t}$ per day, and the water content stabilizes at $60 \%-70 \%$.

The OW-OL mode is superior to the WW-OL mode on water-flooding recovery. In the OW-OL mode, more water can be injected to the whole IWD strata containing high-permeability sandstones, and most oil is produced from low-permeability layered-LPTOLs with less water content. The vertical water-flooding efficiency is high at the production side, and the whole displacement is more balanced in the independent development LPTOLs, so the recovery is greater. In contrast, there is still serious vertical heterogeneity at the producing side in the WW-OL model. Under the WW-OL model, although the wells are simultaneously producing LPTOLs and HPOLs with high water content, more injected water will enter the HPOLs with inefficient displacement and low recovery, and the displacement efficiency of LPTOLs is affected. However, the oil-well perforation cannot completely avoid the HPOLs with high water content in the practical development, so under the conditions permitting, it is a priority to design the OW-OL mode considering reasonable $C V$.

\section{Conclusions}

(1) The core of IWD is the SHF and strata series combination in shallow 
multi-layer reservoirs, which are composed of both layer-type LPTOLs and HPTOLs. In the meanwhile time, the crosslink HPTOLs are also utilized to absorb more injected water, in order to help LPTOLs economic performance. According to the spatial distribution of the perforated HPTOLs and LPTOLs, OW-OL and WW-OL two modes are proposed.

(2) According to the fluid flow equations of coupled matrix and fracture, a discrete numerical simulation model with structured matrix grids and unstructured virtual fracture grids is given. A numerical simulation method of reservoir is proposed to deal with horizontal fracture effectively. Based on this model, the influence of different factors on the development of shallow LPTOLs are analyzed. It is suggested that the flow coefficient should be considered firstly when selecting fracturing layers. Secondly, we should consider whether the water-wells and oil-wells can connect with each other in the horizon, and then providing enough pressure to overcome the threshold pressure in LPTOLs is also necessary. Finally, the initial oil saturation of LPTOLs, which can be also regarded as the remaining oil saturation after conventional water-flooding before, should be much lower. Through the study of the effective limits of the multi-layer sandstone reservoirs, the technical and economic parameters of the LPTOLs are optimized, and the field test is effectively guided.

(3) Multi-layer sandstone reservoirs have the conditions for large-scale application of IDW for LPTOLs. Not only new infilling well pattern can be transferred into IWD \& SHF, but also long-time waterflooding block can adopt IWD after sealing the layers with high permeability high water content. According to the different LPTOLs and their remaining oil potential, different development methods can be used to promote the IWD test of LPTOLs and field application. Therefore, IWD of LPTOLs is not only suitable for Chinese sandstone oilfield, but also has a general significance for other multi-layer sandstone reservoirs owing high potential LPTOLs.

\section{Acknowledgement}

The study was supported by National Natural Science Foundation of China (11702300), PetroChina Innovation Foundation (2017D-50070208) and the Key Laboratory of Fluid - Solid Coupling System Mechanics, Chinese Academy of Sciences.

\section{Nomenclature}

$m \quad$ matrix mark $f$ fracture mark

$l \quad$ oil or water phase mark $\varphi$ porosity

$V \quad$ volume, $\mathrm{m}^{3} \mathrm{~b}$ volume coefficient reciprocal

$S \quad$ saturation $T$ transmissivity, $\mathrm{m}^{3} \cdot \mathrm{MPa}^{-1}$

$P \quad$ pressure, MPa $\gamma$ gravity, $\mathrm{kg} \cdot \mathrm{m}^{-3}$

$z \quad$ depth, $\mathrm{m} K$ permeability, $\mathrm{mD}$

$\mu \quad$ viscosity, mPa.s $K_{\mathrm{r}}$ relative permeability

$t \quad$ time, $\mathrm{h} x_{\mathrm{n}}$ distance from any point to the fracture surface, $\mathrm{m}$

$\mathrm{i}, \mathrm{j}, \mathrm{z} \quad$ matrix grid coordinates $n_{\mathrm{f}}$ fracture grid label

$R \quad$ material equilibrium residual $\mathrm{c}$ grid mark of the point

a adjacent grid mark $B$ total number of the adjacent grids

$n \quad$ previous iteration step $n+1$ iterative step

$\Gamma_{\mathrm{w}} \quad$ inner boundary $\Gamma_{\mathrm{e}}$ outer boundary

$M_{\mathrm{SD}} \quad$ flow efficiency standard deviation $M_{\mathrm{a}}$ average flow efficiency, $\mathrm{mD} \cdot \mathrm{m} \cdot(\mathrm{mPa} \cdot \mathrm{s})^{-1}$

$q_{\mathrm{m}, \mathrm{f}, 1} \quad$ flow exchange from matrix to fracture, $\mathrm{m}^{3} q_{\mathrm{w}, 1}$ L-phase flow volume from fracture to well, $\mathrm{m}^{3}$

$A_{\mathrm{f}, \mathrm{m}} \quad$ acreage of the fracture surface in the matrix unit, $\mathrm{m}^{2}$

$\bar{d}_{\mathrm{f}, \mathrm{m}} \quad$ average distance from the matrix unit center to the internal fracture unit center, $\mathrm{m}^{2}$

$\Delta P_{\mathrm{m}} \quad$ pressure difference between the two iterations of the matrix grid, $\mathrm{MPa}$

$\Delta P_{\mathrm{f}} \quad$ pressure difference between the two iterations of the fracture grid, MPa

\section{Appendix A. Basic parameters of case A model}

The basic parameters of case A model are shown in Table 7, and this model can be set to adopt OW-OL or WW-OL five-point well pattern development modes. This case is designed to study the effect of IWD in the reservoirs with small $C V$ and high permeability. 
Table 7

Specific parameters of each reservoir in case A.

\begin{tabular}{|c|c|c|c|c|c|}
\hline Oil layers & Layer number & Thickness/m & Permeability/mD & Oil viscosity/mPa's & Flow coefficient $/ \mathrm{mD} \cdot \mathrm{m} \cdot(\mathrm{mPa} \cdot \mathrm{s})^{-1}$ \\
\hline \multirow[t]{13}{*}{ LPTOLs } & 1 & 0.2 & 5.0 & 10.0 & 0.1 \\
\hline & 2 & 0.2 & 5.0 & 10.0 & 0.1 \\
\hline & 4 & 0.2 & 10.0 & 10.0 & 0.2 \\
\hline & 5 & 0.2 & 10.0 & 10.0 & 0.2 \\
\hline & 6 & 0.5 & 10.0 & 10.0 & 0.5 \\
\hline & 9 & 0.5 & 10.0 & 10.0 & 0.5 \\
\hline & 10 & 0.5 & 20.0 & 10.0 & 1.0 \\
\hline & 11 & 0.5 & 20.0 & 10.0 & 1.0 \\
\hline & 12 & 0.5 & 30.0 & 10.0 & 1.5 \\
\hline & 13 & 0.5 & 30.0 & 10.0 & 1.5 \\
\hline & 14 & 0.5 & 40.0 & 5.0 & 4.0 \\
\hline & 19 & 0.5 & 40.0 & 5.0 & 4.0 \\
\hline & 20 & 1.0 & 20.0 & 10.0 & 2.0 \\
\hline HPTOL & 1 & 1.0 & 200.0 & 10.0 & 20.0 \\
\hline
\end{tabular}

As shown in Table 7, a total of 20 LPTOLs and one $1 \mathrm{~m}$ HPTOL are designed in this case, their average layer thickness is $0.5 \mathrm{~m}$, the average flow coefficient is 2.6 $\mathrm{mD} \cdot \mathrm{m} \cdot(\mathrm{mPa} \cdot \mathrm{s})^{-1}$, and the $C V$ is 7.5 .

\section{Appendix B. Basic parameters of case B model}

The basic parameters of case B model are shown in Table 8, and this model can be set to adopt OW-OL or WW-OL five-point well pattern development modes. This case is designed to study the effect of IWD in the reservoirs with medium $C V$ and high permeability.

Table 8

Specific parameters of each reservoir in case B.

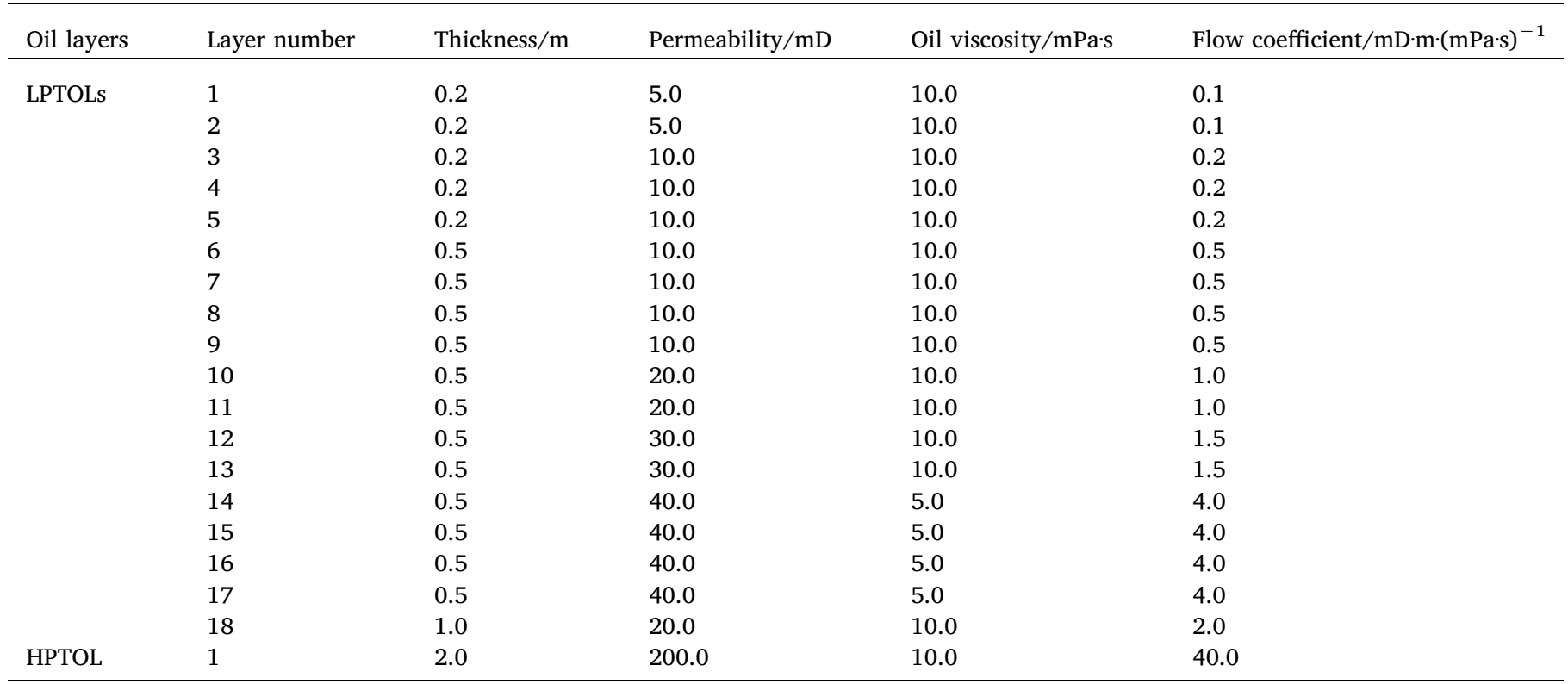

As shown in Table 8, a total of 18 LPTOLs and one $2 \mathrm{~m} \mathrm{HPTOL}$ are designed in this case, their average layer thickness is $0.5 \mathrm{~m}$, the average flow coefficient is 3.5 $\mathrm{mD} \cdot \mathrm{m} \cdot(\mathrm{mPa} \cdot \mathrm{s})^{-1}$, and the $C V$ is 11 .

\section{Appendix C. Basic parameters of case C model}

The basic parameters of case C model are shown in Table 9, and this model can be set to adopt OW-OL and WW-OL five-point well pattern development ways. The case is designed to study the effect of IWD in the reservoirs with large $C V$ and high average permeability. 
Table 9

Specific parameters of each reservoir in case C.

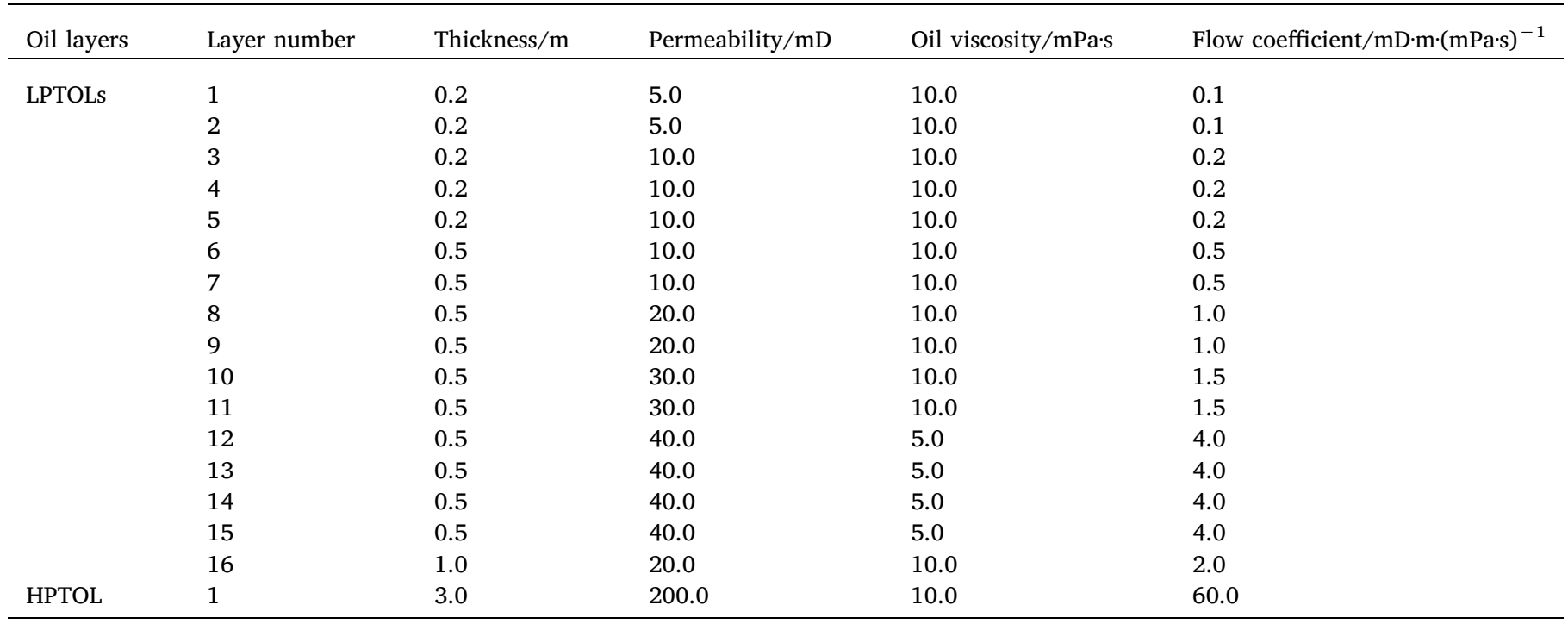

As shown in Table 9, a total of 17 LPTOLs and one $3 \mathrm{~m} \mathrm{HPTOL}$ are designed in this case, their average layer thickness is $0.6 \mathrm{~m}$, the average flow coefficient is 5 $\mathrm{mD} \cdot \mathrm{m} \cdot(\mathrm{mPa} \cdot \mathrm{s})^{-1}$, and the $C V$ is 11.4 .

\section{References}

Cinco, L.H., Samaniego, V.F., Dominquez, A.N., 1978. Transient pressure behavior for a well with a finite-conductivity vertical fracture. Soc. Petroleum Eng. J. 18 (4), 253-264.

Fu, G.Q., Wei, Z.G., Guo, H.W., Chang, M.Y., 2003. Characteristics and recovery method of untabulated reservoirs in Xingnan oilfield. J. Daqing Petroleum Inst. 27 (4), 15-17.

Gao, D.P., Ye, J.G., Hu, Y.L., Dong, Y.F., Zhu, Z.K., Yuan, H., Huang, L., 2015. An evaluation model for stratified water injection in multilayer reservoirs. Petroleum Explor. Dev. 42 (6), 711-715.

Gao, D.P., Ye, J.G., Li, Q., Shi, C.F., Hou, S.J., Ji, S.H., Huang, L., 2017. An independent development method of low-permeability thin layers of Chang Yuan reservoir with extreme high water cut. Oil Gas Geol. 38 (1), 181-188.

Gao, D.P., Ye, J.G., Liu, Y.W., Pan, S.Q., Hu, Y.P., Yuan, H., 2016. Coupled numerical simulation of multi-layer reservoir developed by lean-stratified water injection. J. Petroleum Explor. Prod. Technol. 6 (4), 1-9.

Hajibeigi, H., Karvounis, D., Jenny, P., 2011. A hierarchical fracture model for the interative multiscale finite volume method. J. Comput. Phys. 230 (24), 8729-8743.

Hu, W., Yan, C., Chen, Z.T., et al., 2013. Study of reasonable well planning for third infilling in Xing6 Central, Daqing Oilfield. PGRE Petroleum Geol. Recovery Effic. 20 (6), 73-75.

Jalali, M., Embry, J.M., Sanfilippo, F., Santarelli, F.J., Dusseault, M.B., 2016. Cross-flow analysis of injection wells in a multilayered reservoir. Petroleum 2 (3), 273-281.

Larsen, L., November 2011. Horizontal fractures in single and multi-layer reservoirs. In: Presented at the SPE Canadian Unconventional Resources Conference Held in Calgary, Alberta, Canada. SPE-147004.

Li, Q.Y., Zhang, J.Q., Deng, B.R., Chang, J.H., Li, H., Liu, S.S., Xu, X.M., 2011. Grey decision-making theory in the optimization of strata series recombination programs of high water-cut oilfields. Petroleum Explor. Dev. 38 (4), 463-468.

Liu, D.C., Wang, Q.M., Li, B.H., 1996. Development of Multi-sandstone Reservoirs in Daqing Oil Field. Petroleum Industry Press.

Liu, H., Pei, X.H., Jia, D.L., Sun, F.C., Guo, T., 2017. Connotation, application and prospect of the fourth-generation separated layer water injection technology. Petroleum Explor. Dev. 44 (4), 644-651.

Liu, H., Pei, X.G., Luo, K., 2013. Current status and trend of separated layer water flooding in China. Petroleum Explor. Dev. 40 (6), 733-737.

Liu, R.J., Liu, H.Q., Li, X.S., Liu, H.Z., 2009. Evaluation model of nitrogen gas flooding in low-permeability reservoir based on grey relation grade. J. China Univ. Petroleum 33
(3), 90-94.

Mazen, A., Chun, H., Kamy, S., et al., 2014. A critical review on use of polymer microgels for conformance control purposes. J. Petroleum Sci. Eng. 122, 741-753.

Mustoni, J.L., Cabrera, F.A., Manrique, E.J., Norman, C., April 2012. Application of a thermally activated particle system for improved sweep efficiency in a multi-layer, geologically complex waterflood. In: Presented at the SPE Improved Oil Recovery Symposium Held in Tulsa, Oklahoma, USA. SPE-153331.

Narasimhan, T.N., Palen, W.A., April 1979. A purely numerical approach for analyzing fluid flow to a well intercepting a vertical fracture. In: Presented at the SPE California Regional Meeting Held in Ventura, California. SPE-7983.

Osiptsov, A.A., 2017. Fluid Mechanics of hydraulic fracturing: a review. J. Petroleum Sci. Eng. 156, 513-535.

Sung, W., Ertekin, T., May 1987. Performance comparison of vertical and horizontal hydraulic fractures and horizontal boreholes in low permeability reservoirs: a numerical study. In: Presented at the SPE Low Permeability Reservoirs Symposium Held in Denver, Colorado. SPE-16407.

Wu, X.C., Xiong, C.M., Han, D.K., He, L., Gao, S.L., Xu, H.B., Dong, F., Ren, F.X., October 2014. A new IOR method for mature waterflooding reservoirs: "Sweep control technology". In: Presented at the SPE Asia Pacific Oil \& Gas Conference and Exhibition Held in Adelaide, Australia. SPE-171485.

Xiao, P.F., Yang, Z.M., Wang, X.W., Xiao, H.M., Wang, X.Y., 2017. Experimental investigation on $\mathrm{CO}_{2}$ injection in the Daqing extra/ultra - low permeability reservoir. J. Petroleum Sci. Eng. 149, 765-771.

Xiong, C.M., Tang, X.F., 2007. Technologies of water shut-off and profile control: an overview. Petroleum Explor. Dev. 34 (1), 83-88.

Zeng, B.Q., Cheng, L.S., Li, C.L., 2011. Low velocity non-linear flow in ultra-low permeability reservoir. J. Petroleum Sci. Eng. 80 (1), 1-6.

Zhao, Y.S., Wang, X.J., Lan, Y.B., Chang, M.Y., 2001. Discussion on the model of induced fracture geometry. Petroleum Explor. Dev. 28 (6), 97-98.

Zhou, W., He, S.R., Zhao, C.S., 1982. Operations and their characteristics in Daqing oil field. Petroleum Explor. Dev. 3, 66-72.

Zhou, Z.J., Zhao, J.B., Zhou, T., Huang, Y.M., 2017. Study on in-depth profile control system of low-permeability reservoir in block H of Daqing oil field. J. Petroleum Sci. Eng. 157, 1192-1196.

Zhu, Y.Y., Hou, Q.F., Jian, G.Q., Ma, D.S., Wang, Z., 2013. Current development and application of chemical combination flooding technique. Petroleum Explor. Dev. 40 (1), 90-96. 